\title{
autêntica
}

\author{
ARTIGOS
}

\section{Contribuições do programa institucional de bolsas de iniciação à docência - PIBID na carreira de professores experientes}

Regina Magna Bonifácio Araújo ${ }^{1}$

Valdete Alves Batista ${ }^{2}$

Vera Madalena da Rocha Maia $^{3}$

\section{RESUMO}

O texto apresenta um recorte da pesquisa intitulada Desenvolvimento Profissional Docente e Inovação Pedagógica: estudo exploratório sobre contribuições do PIBID, buscando compreender em que medida o professor supervisor do PIBID se beneficia do Programa, levando-se em conta sua prática pedagógica bem como suas reflexões e transformações sobre o fazer profissional e a carreira docente. Esta investigação articula experiências e estudos de grupos de pesquisa de três Programas de Pós-Graduação em Educação situados nas regiões Nordeste e Sudeste do Brasil, envolvendo professores da educação básica, graduandos, mestrandos, doutorandos, mestres e doutores, entre bolsistas e colaboradores. Usando a metodologia qualitativa, foram entrevistados 90 professores supervisores do PIBID, 30 em cada localidade em que ocorreu a pesquisa. Os dados analisados pelas pesquisadoras referem-se a 30 sujeitos do Estado de Minas Gerais e eles trouxeram à tona muito mais que o impacto do PIBID na carreira profissional dos professores supervisores. Os dados coletados e as análises criteriosas dessas informações revelaram que os docentes, em sua grande maioria, identificam-se totalmente com a profissão escolhida e que, apesar de cientes dos inúmeros desafios que encontram no dia a dia da carreira, sobretudo na escola pública, continuam acreditando no potencial transformador da educação. Ainda, registra-se a compreensão da importância de sua participação e atuação nos projetos, evidenciando ganhos para a comunidade escolar, para si mesmos e, principalmente, para os licenciandos, futuros professores, cuja formação prática se deve, em parte, ao papel que desempenham junto ao PIBID

\section{PALAVRAS-CHAVE}

Iniciação à Docência; Formação de Professores; PIBID

1 Professora Adjunto III do Departamento de Educação da UFOP e do Programa de Pós-graduação em Educação - Mestrado. Pesquisadora do Obeduc - UFOP. Pós-doutorada pela Universidade de Lisboa, doutora pela Unicamp e mestre pela UFJF. regina.magna@hotmail.com

2 Professora da rede pública estadual de ensino, anos iniciais, na E.E. "Dr. Gomes Freire”, em Mariana/MG. É pesquisadora do Obeduc-UFOP. valdetealvesbatista669@gmail.com- Lattes:cnpq.br/7337141410838620

3 Professora de Língua Portuguesa, nos anos finais do Ensino Fundamental. Leciona na E.M. "Dom Oscar de Oliveira”, em Mariana/MG. É pesquisadora do Obeduc-UFOP. E-mail: maia.verarocha@gmail.com - Lattes: cnpq.br/1342001958228096 


\title{
autêntica
}

\begin{abstract}
The text presents a review of the research entitled Teaching Professional Development and Pedagogical Innovation: an exploratory study about PIBID contributions, seeking to understand to what extent the PIBID supervising teacher benefits from the Program, taking into account its pedagogical practice as well as its reflections and Transformations about professional work and the teaching career. This research articulates the experiences and studies of research groups from three Postgraduate Education Programs located in the Northeastern and Southeastern regions of Brazil, involving basic education teachers, undergraduate students, masters, doctoral students, masters and doctors, among scholars and collaborators. Using the qualitative methodology, 90 supervisors of the PIBID were interviewed, 30 in each location in which the research was conducted. The data analyzed by the researchers refer to 30 subjects from the State of Minas Gerais and they brought up much more than the impact of PIBID on the professional career of supervisors. The data collected and the careful analysis of this information revealed that the majority of teachers are totally identified with the chosen profession and that, despite being aware of the many challenges they face in their day to day career, especially in the public school, Continue to believe in the transformative potential of education. Also, there is an understanding of the importance of their participation and performance in the projects, evidencing gains for the school community, for themselves and especially for the graduates, future teachers, whose practical training is due, in part, to the role that with PIBID
\end{abstract}

\section{KEY WORDS}

Introduction to Teaching; Teacher training; PIBID 


\section{autêntica}

\section{INTRODUÇÃO}

O tema da formação de professores e desenvolvimento profissional docente é pauta recorrente de debates, pesquisas, seminários e de literatura especializada, dada a sua relevância no cenário educacional, não somente no Brasil. Quando se fala em políticas ou reformas educacionais, quer do ponto de vista pedagógico/ administrativo, quer do ponto de vista profissional, as discussões passam necessariamente pela figura do professor. Daí, nada mais natural que se reforcem os discursos sobre a necessidade de se formar bem esse profissional e, mais ainda, sobre a necessidade de se continuar investindo na sua formação ao longo da carreira. No entanto, apesar do consenso em torno da importância de uma boa formação inicial e continuada para o docente, a carreira não tem muitos atrativos e, em não raros casos, o futuro professor desiste da profissão antes mesmo de nela ingressar.

Diante disso, consideramos a relevância de iniciativas como o PIBID - Programa Institucional de Bolsas de Iniciação à Docência, do qual falaremos adiante. Através do PIBID, muitos licenciandos bolsistas têm a oportunidade de vivenciar a experiência docente na escola básica muito antes de concluir sua licenciatura. Diferentemente do estágio curricular, o PIBID permite aos futuros professores relacionar a teoria acadêmica e a prática pedagógica em lócus, conhecendo a dinâmica da escola, suas demandas, sua realidade e com possibilidades reais de se apropriarem dos processos pedagógicos que nela se desenvolvem. Segundo Luckesi e Passos (1996), adquirir conhecimentos não é compreender a realidade retendo informação, mas utilizar-se das informações para conhecer o novo e avançar, pois, quanto maior for o entendimento do mundo, mais satisfatória será a ação do sujeito sobre este. É exatamente esse raciocínio que está implícito nos objetivos do PIBID, como constatamos, por exemplo, no item IV, do art. $3^{\circ}$ do Decreto $n^{\circ} 7.219$ de 2010, que instituiu o PIBID:

IV - inserir os licenciandos no cotidiano de escolas da rede pública de educação, proporcionando-lhes oportunidades de criação e participação em experiências metodológicas, tecnológicas e práticas docentes de caráter inovador e interdisciplinar que busquem a superação de problemas identificados no processo de ensino-aprendizagem. (BRASIL, 2010)

Não bastasse esse aspecto extremamente positivo do PIBID, há que se falar do professor da escola básica, que acolhe os bolsistas do Programa e com eles desenvolve essa parceria de que falamos. É esse docente, chamado no âmbito do PIBID de professor supervisor, quem em última instância, possibilita à universidade acessar a escola básica e vice-versa. No entanto, muito mais importante que ser uma ponte entre as instituições, é o fato desse docente supervisor do PIBID estar em constante formação no curso do Programa. Partindo dessa constatação, o Observatório da Educação (Obeduc) da UFOP (Universidade Federal de Ouro Preto) desenvolve desde 2013, em rede com a UNIFESP (Universidade Federal de São Paulo) e a UECE (Universidade Estadual do Ceará) a pesquisa intitulada Desenvolvimento Profissional Docente e Inovação Pedagógica: estudo exploratório sobre contribuições do PIBID, buscando compreender em que medida esse professor supervisor do PIBID se beneficia do Programa, levando-se em conta sua prática pedagógica bem como suas reflexões e transformações sobre o fazer profissional e a carreira docente.

Trata-se de uma pesquisa extensa, tanto em termos do número de pesquisadores envolvidos nos três núcleos participantes e da amostra dos sujeitos da pesquisa, quanto ainda do ponto de vista de sua duração, com início em 2013 e término previsto para 2017. Intitulada "Desenvolvimento Profissional Docente e Inovação Pedagógica: estudo exploratório sobre contribuições do PIBID" esta pesquisa articula experiências e estudos de grupos de pesquisa de três Programas de Pós-Graduação em Educação situados nas regiões Nordeste e 
Sudeste do Brasil, como já mencionado, e envolve professores da educação básica, graduandos, mestrandos, doutorandos, mestres e doutores, entre bolsistas e colaboradores ${ }^{4}$.

Para empreender essa pesquisa em rede, foram definidas e cumpridas várias etapas que compreenderam o estudo bibliográfico e a socialização das leituras; o levantamento dos dados educacionais dos municípios onde a pesquisa foi realizada e dos dados referentes aos projetos do PIBID nas instituições parceiras; a leitura dos editais do PIBID; o mapeamento das escolas participantes e dos professores supervisores; a construção do protocolo de pesquisa, definição dos instrumentais éticos de coleta de dados, aplicação do questionário e realização das entrevistas; organização, análise e consolidação dos resultados. Após a realização das entrevistas em cada núcleo, as mesmas foram codificadas com o auxílio do software NVIVO9. Definiu-se também como recorte para a pesquisa o período compreendido entre os anos de 2009 a 2013, e cada núcleo mapeou os municípios que participaram da pesquisa. No caso da UFOP, as escolas participantes e os professores supervisores são dos municípios mineiros de Mariana e Ouro Preto. Toda a pesquisa, desde sua fase preliminar até a discussão dos resultados, se norteou por duas principais linhas, ou Nós, a saber: Desenvolvimento Profissional Docente e Inovação Pedagógica. Esses Nós se desdobram em vários Subnós, cada qual relacionado a um aspecto da vida profissional e da prática pedagógica do professor supervisor, nomeado "Sujeito da Profissão", justamente um dos Subnós do Desenvolvimento Profissional Docente, e que é o centro de interesse deste texto. A referida pesquisa, em sua fase final, traz à luz dados muito interessantes que apontam para o aspecto extremamente positivo de uma aproximação maior entre as instituições formadoras de docentes e a escola básica, como poderemos verificar quando da discussão dos resultados. Neste texto, apresentaremos os resultados mais diretamente ligados aos Sujeitos da Profissão, que traduzem bem os sentimentos, expectativas e as reflexões de muitos de nossos professores da educação básica.

\section{CONHECENDO O PIBID - PROGRAMA INSTITUCIONAL DE BOLSAS DE INICIAÇÃO À DOCÊNCIA}

Criado pela Coordenação de Aperfeiçoamento de Pessoal de Nível Superior - CAPES, vinculada ao Ministério da Educação - MEC, o Programa Institucional de Bolsa de Iniciação à Docência - PIBID foi proposto no ano de 2007, tendo seu início em 2009 e regulamentação em 24 de junho de 2010, por meio do decreto n 7.219 , pelo Ministro da Educação, Fernando Haddad, no então governo de Luiz Inácio Lula da Silva. Quando instituído, este programa seria desenvolvido por Instituições de Ensino Superior (IES) públicas, em parceria com escolas do ensino básico, também da rede pública.

Atualmente, o PIBID pode ser desenvolvido por IES privadas e sua principal meta é oferecer bolsas de iniciação à docência aos alunos dos cursos de licenciatura, passando a inseri-los no contexto escolar. Com isso, o estudante bolsista do PIBID, desde o início de sua formação acadêmica, desenvolve atividades pedagógicas, no âmbito escolar, sob a supervisão do coordenador do projeto, docente da universidade e do docente da escola na qual está inserido, que também recebem bolsas ao participarem deste programa.

Os principais objetivos do PIBID são incentivar a formação docente em nível superior para atuação na educação básica, melhorar a qualidade da formação inicial de professores nos cursos de licenciatura, inserir os licenciandos no cotidiano da escola pública (BRASIL, 2016). Desde sua criação, o programa vem possibilitando um contato direto dos futuros docentes com a prática pedagógica, independente do estágio, que ocorrerá no período previsto pelo projeto pedagógico de cada curso. A experiência com o PIBID tem se mostrado

4 A pesquisa conta atualmente com a colaboração de 72 pesquisadores nos três núcleos e 90 participantes. Fonte: http://obeducuece.wix.com/pesquisa\#cvcvvg/ mainPage 


\section{autêntica}

importante na formação dos licenciandos, oportunizando um contato direto com a realidade da escola, seus desafios, suas limitações e potencialidades.

\section{FORMAÇÃO DOCENTE E INOVAÇÃO}

A formação e o desenvolvimento profissional docente são temas relevantes que têm merecido, nos últimos anos, a atenção de muitos pesquisadores e de instituições formadoras. Por entender que a formação inicial representa uma etapa importante que antecede a inserção do docente na profissão, é possível afirmar que o desenvolvimento profissional está intimamente relacionado a esta primeira etapa e, obviamente, à formação continuada, e que não há limites que se estabeleçam para o professor desenvolver-se profissionalmente. É importante destacar também que o desenvolvimento profissional docente, a priori, deve se efetivar em práticas que incentivem a colaboração entre os pares, privilegiando as escolas, com suas rotinas, seu público-alvo, seus contextos específicos e demandas, como o lócus preferencial de formação. Sobre esse ponto de vista, Imbernón (2001, p. 15) aponta que:

"a formação assume um papel que transcende o ensino que pretende uma mera atualização científica, pedagógica e didática e se transforma na possibilidade de criar espaços de participação, reflexão e formação para que as pessoas aprendam e se adaptem para poder conviver com a mudança e as incertezas"

Dessa forma, entende-se que o desenvolvimento profissional ocorre através da socialização de saberes e nas práticas colaborativas, no entanto, trata-se de algo subjetivo que depende de uma atitude pessoal, ainda que seus efeitos incidam no coletivo e possam propiciar reflexões entre os pares sobre uma nova cultura docente.

As práticas individualistas, ainda tão comuns nas escolas, contrapõem-se aos anseios do desenvolvimento profissional, mesmo que sirvam de pilares para o amadurecimento profissional. Assim, embora reconhecendo que são inúmeros os meios que se constituem como oportunidades de formação continuada (conselhos de classe, palestras, cursos, seminários, etc.) muitos pesquisadores defendem a tese de que é no interior das escolas, espaço real e coletivo, que o professor deve desenvolver sua profissionalidade. Day (2001, p. 16) defende que os professores devem ter "oportunidade para participar numa variedade de atividades formais e informais indutoras de processos de revisão, renovação e aperfeiçoamento do seu pensamento e ação e, sobretudo, do seu compromisso profissional." Sobre esse aspecto, a Lei de Diretrizes e Bases da Educação Nacional - LDBEN, Lei 9.394/96, foi uma incursão governamental que também impulsionou os professores, propondo debates e reflexões sobre a importância da formação continuada.

Em entrevista à revista digital Gestão Escolar, quando perguntado sobre a colaboração dos coordenadores pedagógicos na mudança de paradigmas dos docentes, Imbernón (2011) fala que, aos poucos, os coordenadores vão se conscientizando da necessidade de modelos formativos mais reflexivos, que se utilizem do contexto e do local de trabalho para, num exercício de reflexão coletiva e de ação colaborativa, produzir os saberes necessários à superação dos problemas que afetam o trabalho e a prática docente. O entrevistado diz ainda que essas práticas colaborativas são essenciais "para criar espaços de aperfeiçoamento, inovação e pesquisa nos quais sejam analisadas as dúvidas individuais e coletivas dos professores" e que as verdadeiras mudanças devem refletir na resolução das situações-problemas da sala de aula.

Reafirma-se aqui a ideia da importância do trabalho coletivo e também da predisposição pessoal para o aprendizado, a reflexão e a mudança. Torna-se evidente, no entanto, que não é o simples fato de estar na 


\section{autêntica}

escola e de desenvolver uma prática escolar concreta que garante a presença das condições mobilizadoras de um processo formativo. Uma prática repetitiva, mecânica, não favorece esse processo. A esse respeito, Nóvoa (1995) defende a ideia de que a formação de professores deve levar em consideração os aspectos pessoal e profissional, pelo fato de sua prática estar permeada pelas experiências vividas, não somente na sala de aula, mas também na vida em sociedade. É com base nessa formação que se coloca em discussão a relevância das práticas individuais para o processo educativo e para o desenvolvimento profissional.

Sabe-se que o individualismo é cultural na profissão docente e, muitas vezes, é tão inerente ao fazer pedagógico que os próprios professores não se dão conta dessa prática. Quando se diz que práticas individuais são inerentes à docência, refere-se não só às atitudes dos docentes mas também à estrutura da escola, à escassez de tempo para atividades coletivas, à composição dos currículos e aos discursos institucionalizados na primeira pessoa do singular. Uma série de fatores, portanto, favorecem práticas individuais nas escolas, o que nem sempre é negativo, se pensarmos que importantes e necessárias reflexões nascem no indivíduo para se estenderem ao coletivo. No entanto, como lembra Farias (2006, p. 87) a respeito do individualismo do professor: "Esse modo de cultura docente apresenta-se como um terreno fértil para o cultivo do pragmatismo, da passividade e da reprodução conservadora, ao se afastar de situações que possibilitem a troca de experiência, a renovação do pensamento e da prática do professor".

Seria ingenuidade, no entanto, acreditar que toda e qualquer prática coletiva entre os docentes de uma escola represente, de fato, uma prática colaborativa. Se as atividades propostas (ou impostas) ao grupo de professores são na verdade mecanismos de controle de poder e que pouco ou nada têm a ver com a formação dos docentes, seu sentido é esvaziado e se tornam um conjunto de individualidades. Mesmo que a aparente dicotomia entre a prática individual e a colaborativa não esteja muito bem resolvida no pensamento do professor, uma não exclui a outra, visto que o trabalho coletivo pressupõe a independência e a autonomia dos sujeitos que, focados no mesmo fim, qual seja o desenvolvimento da escola como um todo, são capazes de articular ideias e ações pelo bem comum. Essa conduta de colaboração entre os pares é, no entendimento de Farias (2006, p. 98), “(...) condição de sobrevivência da profissão de professor, em um contexto social em que o conhecimento é a principal forma de trabalho e produção".

As discussões em torno do individualismo como parte da cultura docente têm lugar neste texto devido à discussão que se propõe também a respeito de inovação no contexto educacional, cuja dificuldade de implementação muitas vezes é atribuída à postura do professor, pouco afeito a mudanças. Sem entrar no mérito da dificuldade em se definir com clareza o termo "inovação pedagógica", podemos nos ater ao campo semântico da mudança, da ruptura, dos saltos, da estranheza mesmo. Fino (2008) apresenta uma série de características que dão conta de clarear o sentido do termo "inovação pedagógica", mas o melhor caminho proposto pelo autor para conceituar o termo talvez resida no que ele não é. Portanto, segundo o autor a inovação pedagógica não é tradicional; não resulta somente de uma boa formação docente; não acontece de fora para dentro, mas pressupõe reflexão crítica e autocrítica, partindo de uma opção individual ou local; nem sempre está alinhada com o currículo, podendo haver tensões; e finalmente, apesar do alto desenvolvimento científico, inovação pedagógica não é sinônimo de adoção de recursos tecnológicos na educação. 0 autor chama a atenção para os cuidados que os pesquisadores devem ter em relação à definição do termo inovação pedagógica para que não seja tomado como sinônimo de qualquer coisa e, ao mesmo tempo, para a dificuldade em estreitar-Ihe o campo quando das investigações dos acontecimentos nos ambientes formais e informais de aprendizagem. Quer dizer que nem tudo é inovação, mas que também não é possível enumerar as ações, os acontecimentos e eventos que se constituem como tal, sobretudo em contextos de ensino e aprendizagem. Entretanto, é fato que a sociedade do século XXI, plenamente adaptada às tecnologias da 


\section{autêntica}

informação, pode prescindir da escola tradicional para produzir conhecimento, uma vez que tudo está ao alcance da mão, o tempo todo, não sendo a produção do conhecimento função exclusiva da escola. Isso não é novidade para ninguém, como não é novidade o discurso de que a escola tradicional precisa mudar para acompanhar as demandas dos novos tempos. Não se trata apenas de equipar as escolas com modernos equipamentos tecnológicos e capacitar professores e alunos para utilizá-los eficientemente, embora isso seja muito importante para qualquer mudança que se proponha no campo pedagógico. Não cabe somente aos recursos materiais nem tampouco aos profissionais da educação garantir o sucesso de tais mudanças. Principalmente no caso do professor, não é possível que a ele seja atribuída a tarefa hercúlea de transformar a sociedade, ainda mais nesses novos tempos em que a escola disputa a audiência dos alunos com as redes sociais e em que o trabalho docente ainda se encontra sob forte controle administrativo. Muitas outras transformações estruturais e culturais no âmbito educacional são necessárias para dar respostas às exigências do mundo contemporâneo. E se o professor parece resistir a mudanças, é preciso levar em consideração que ele tem um compromisso ético com a sua profissão e deseja participar do debate acerca das medidas propostas e talvez esse aspecto, muito positivo por sinal, justifique sua aparente desconfiança. Como salienta Farias (2006, p.71),

O engajamento ou não dos professores a propostas de mudança é mediatizado por elementos de julgamento que os ajudam a balizar o significado da mudança, seus benefícios, as desvantagens, os ganhos, as perdas, as condições de trabalho, as exigências pedagógicas e cognitivas em relação à sua atuação.

Isso implica considerar que o professor que assim age é um profissional crítico, ético e preocupado de fato com os resultados e os benefícios que tais mudanças podem acarretar para o desempenho dos alunos. É natural que o professor tenha receio de mudar, pois a educação não é um campo experimental, mas um espaço de relações pedagógicas e interpessoais cada dia mais desafiantes, principalmente nas escolas públicas. Pode-se dizer que o professor crítico e reflexivo, ao resistir a determinadas mudanças, está comprometido, seguindo ainda o pensamento de Farias (2006, p,75), com "a emancipação cultural, política e social, tanto sua quanto de seus alunos".

Mas nem sempre é possível ou conveniente resistir a mudanças, uma vez que elas são necessárias e urgentes, devendo, no entanto, ser fruto de discussões e elaborações coletivas, e isso só pode ocorrer em contextos colaborativos, rompendo com práticas isoladas e de pequenos grupos, visando ao sucesso das decisões. Cabe ressaltar que a centralidade do professor no processo de elaboração e implementação de mudanças não exime o Estado de sua responsabilidade em relação à garantia de uma educação pública e de qualidade.

Essas reflexões e outras não apresentadas aqui serviram de referencial para a análise dos dados coletados na pesquisa Desenvolvimento Profissional Docente e Inovação Pedagógica: estudo exploratório sobre contribuições do PIBID, principalmente nos sub-subnós mais diretamente relacionados aos professores supervisores do Programa, como será apresentado a seguir.

\section{O QUE DIZEM OS DADOS DA PESQUISA}

Na pesquisa descrita acima, foram ouvidos, em cada núcleo, trinta professores ativos e egressos do PIBID, nomeados no âmbito do Programa, "professores supervisores" e na pesquisa, "sujeitos da profissão". Procurou-se diversificar ao máximo a área de atuação desses docentes, passando por diversas disciplinas, por todos os níveis de educação básica, nas modalidades regular e EJA. Todos os entrevistados são professores de escolas das redes municipal e estadual, dos municípios de Mariana e Ouro Preto. 
Para orientar a coleta, análise e discussão dos dados, foram definidos oito descritores dentro do subnó "sujeitos da profissão" que nortearam a investigação e permitiram ler objetivamente os resultados. Interessava-nos saber como o docente define a sua identidade profissional e a relação do trabalho com a sua pessoalidade. Para tanto, o primeiro descritor tratava justamente da constituição identitária do professor supervisor do PIBID.

Os professores, via de regra, falam com segurança sobre diversos assuntos relacionados ou não ao seu contexto profissional, mas nem todos se dão a conhecer com a mesma naturalidade, por diversos motivos. Como já foi dito anteriormente, o tempo, a estrutura e a dinâmica da escola não favorecem reflexões coletivas e muito menos individuais, talvez seja por isso que muitos entrevistados, nesse ponto da conversa, fizeram um verdadeiro desabafo ao falarem sobre a omissão do Estado e das famílias em relação à educação pública, sobre o desinteresse e a indisciplina dos alunos, sobre a desvalorização da carreira docente, dentre vários outros desafios, como veremos adiante. No entanto, esses sujeitos seguem perseverantes na carreira e nisso não há nenhum paradoxo, uma vez que todos disseram identificar-se com a docência, porque foram influenciados por familiares e outros professores ou porque desenvolveram essa afinidade com a profissão assim que nela ingressaram. A esse respeito, um dos entrevistados diz o seguinte:

(...) tinha aquele exemplo bacana dentro de casa, estudando, trabalhando e acreditando na educação como a salvadora da pátria, e a minha irmã mais velha também já era professora (P38EFE). ${ }^{5}$

O senso comum dos que desconhecem a profissão docente, baseado principalmente em critérios econômicos, muitas vezes produz juízos equivocados como alerta Farias (2006, p.35) ao lembrar que "(...) a escolha pela profissão de professor é vista por muitos como falta de competência para conseguir colocação mais privilegiada, isto é, mais bem remunerada". Embora reconhecendo os altos e baixos da carreira, nenhum dos docentes ouvidos disse estar na profissão por falta de opção no mercado de trabalho. Alguns entrevistados disseram, inclusive, que não conseguem se ver em outra profissão, e que a sua atividade pedagógica é uma missão e eles, vocacionados. Vejamos o que dizem dois desses sujeitos:

(...) se eu tivesse que começar uma nova profissão, eu ia começar de novo no magistério porque, assim, eu realmente gosto do que eu faço e eu tenho verdadeira adoração pela alfabetização (...) (P53PAA)

(...) eu acho que nós que estamos tratando com escola, somos anjos de Deus, escolhidos justamente para vir aqui. Escolhidos a dedo para estar aqui (...) (P40FA).

Os professores lembraram que a identidade docente é construída também a partir de outros papéis sociais que os professores são chamados a desempenhar frente à vulnerabilidade social de crianças e jovens e nas situações em que falta em casa uma referência adulta com disponibilidade para acolher as demandas psicológicas, principalmente de adolescentes e jovens. Assim, os professores “( ...) são desafiados a assumir tarefas educativas básicas para compensar as carências do meio social de origem dos alunos, o que implica significativa diversificação das funções docentes" (Farias, 2006 p.34). Isso dito por uma professora ouvida na pesquisa,

5 O código que figura após cada fala de docente refere-se ao professor supervisor do PIBID, onde P significa Professor, o número que se segue identifica cada docente entrevistado, enquanto as demais letras são as iniciais da disciplina, por exemplo EF (Educação Física), sendo que a última letra sempre varia entre A (ativo no PIBID) ou E (egresso do PIBID). 


\section{DOCENTE}

\section{autêntica}

(...) eu me vejo mais como educadora do que como professora, principalmente, porque o mundo hoje, a sociedade está com outros valores, as famílias são com outras estruturas. Então a gente adota essas crianças de uma forma que professora é mãe, é tudo na vida deles, eu vejo que antes de ensinar eu tenho que educar, preparar e às vezes essa educação não vem de casa, das famílias, sabe? (P38EFE).

Muito mais foi dito pelos entrevistados a respeito de como vêm se constituindo enquanto professores, acumulando experiências, definindo e redefinindo caminhos metodológicos enquanto suas trajetórias se cruzam com a de centenas de alunos e companheiros de profissão. É bem como dizem Oliveri, Jardilino e Diniz (2015, p.121): "O que somos como professores vem da vontade, de gostos, de experiências, de acasos que se consolidam em gestos, rotinas, ações, comportamentos que nos fazem nos identificarmos como professores." Os docentes ouvidos reconhecem que sua inserção no PIBID possibilitou-lhes refletir sobre o fazer pedagógico e sobre a própria carreira, contribuindo assim para que sua identidade profissional seja constituída a partir de uma postura mais consciente e crítica, como aponta o depoimento seguinte:

[O PIBID] serviu para me entender, eu como professor e o outro como aluno (...) e eu me vejo hoje como uma pessoa que está fazendo uma mediação (P44HA).

As escolas públicas, seu currículo e sua organização geral parecem sofrer poucas alterações com o passar dos tempos, mas o mesmo não se pode dizer em relação ao processo de ensino e aprendizagem que se desenvolve no interior das instituições. A cada dia diversificam-se as demandas dos alunos e dos próprios professores, que não mais se contentam com a formação inicial, com metodologias ineficazes, com as interferências em suas aulas, só para citar alguns dos obstáculos que o docente enfrenta no dia a dia da escola. Os professores disseram que, entre os desafios da carreira, talvez o maior seja a desvalorização profissional, e não se referem principalmente à remuneração, outros aspectos igualmente desafiadores contribuem para que o professor se sinta desvalorizado e aviltado no exercício de sua profissão. A conduta do aluno desinteressado e indisciplinado, a falta de infraestrutura adequada para a aprendizagem, a omissão do Estado e dos pais, a ausência de uma equipe multidisciplinar para apoiar o trabalho pedagógico são alguns dos problemas elencados pelos professores e que, segundo eles, são verdadeiros entraves para que o processo de ensino e aprendizagem tenha êxito. E quando o sucesso escolar não acontece, o Estado é o primeiro a cobrar resultados e apontar responsáveis pelo fracasso escolar. Geralmente, o docente está na linha de frente dessa cobrança. Acompanhe o depoimento desse professor:

[um desafio é] a questão metodológica e a avaliação, essa cobrança é uma questão onde o professor que é o culpado pelo sucesso e pelo fracasso do aluno, e é um peso muito grande, uma frustração (P44HA).

Todos os desafios lembrados pelo professor estão presentes com maior ou menor recorrência na maioria das escolas públicas de educação básica e não há como o professor não absorver essas experiências, como foi dito há pouco. Por mais que o docente esteja convicto de sua escolha profissional e ciente dos desafios que são inerentes ao magistério, ainda assim ele se sente muitas vezes fragilizado como cidadão e como profissional, como desabafa o professor P34FA:

(...) temos a dificuldade do aluno, do não querer dele, a gente tem a dificuldade que esbarra na burocracia da própria escola e o impasse dentro dela e a burocracia do sistema no geral que não facilita em nada o trabalho docente. 


\section{autêntica}

A carreira docente não é um caminho fácil a ser percorrido, como nos aponta Ferreira (2009), lembrando que os professores encontram resistências, desestabilizações e falta de sentidos para a educação. Não se trata de uma profissão como tantas outras, porque é permeada de relações interpessoais. No entanto, se num primeiro momento, o docente desestabiliza-se frente a um grande desafio, logo ele se conscientiza da peculiaridade da carreira e parte para a ação, visando à superação dos obstáculos. Um aspecto curioso desse ponto da entrevista, é que alguns professores citaram como um desafio da carreira a falta de oportunidades para formar-se continuamente. Ou seja, o professor quer posicionar-se frente às mudanças da sociedade que se refletem na sua sala de aula e para isso necessita atualizar-se constantemente. Nesse sentido, os entrevistados percebem o PIBID como uma oportunidade ímpar de formação continuada, embora lamentando que apenas poucos professores tenham acesso a essa formação. Sobre isso, Nóvoa $(2000$, p. 38) afirma que "a formação contínua deve estimular uma perspectiva crítico-reflexiva, que forneça aos professores os meios de um pensamento autônomo e que facilite as dinâmicas de autoformação participada". Entretanto, como as oportunidades de ações colaborativas na escola ainda são escassas em virtude principalmente de tempo, infelizmente não se pode garantir que o conhecimento que o professor supervisor do PIBID adquire possa ser socializado com seus pares.

Apesar de reconhecerem as limitações do Programa, de acordo com os relatos dos professores supervisores do PIBID, suas expectativas foram alcançadas. Ao serem perguntados quais motivos os levaram a participar do PIBID e se suas expectativas haviam sido alcançadas, as respostas pareceram bastante positivas, como demonstra este professor supervisor:

(...)Aí o PIBID vem com um gás novo e traz energia nova pra gente, e os trabalhos ficam bons, onde todos os trabalhos desenvolvidos pelo PIBID aqui têm ficado excelentes. E isso tudo me incentivou a participar. Eu acho que minhas expectativas foram alcançadas sim, eu dentro do PIBID tenho feito vários trabalhos e principalmente com ajuda dos meus colegas (P34FA).

O Programa se configura para os docentes como uma ótima oportunidade de formação continuada e de socialização de experiências e conhecimentos com os licenciandos e com a própria universidade, apesar de ser pouco abrangente do ponto de vista da demanda da escola básica. O PIBID representa também a possibilidade de acesso a materiais pedagógicos e equipamentos diversificados, necessários, não acessíveis na maioria das escolas públicas. Veja o que diz este docente ao falar sobre suas expectativas:

O Estado deveria fornecer melhores condições de nível de aprendizado, com os equipamentos

(...) fazer cursos de capacitação de professores...Dar condições para esses professores, para este profissional continuar estudando (P32BA).

Como se pode observar a partir da fala deste professor, embora o PIBID seja considerado como uma intervenção muito positiva para a escola, uma vez que motiva os professores e alunos num contexto de ensino e de aprendizagem inovadores, os relatos revelam a consciência que os professores têm sobre a omissão do Estado em alguns aspectos básicos.

Exatamente por ter um caráter inovador, ao ingressarem no PIBID, os docentes têm dificuldade para compreender a dinâmica do Programa. Somente à medida que os projetos vão se desenvolvendo é que os professores supervisores vão se apropriando de seus objetivos e se inteirando de sua importância. Especialmente nas entrevistas com os supervisores egressos, foi possível observar a relevância do PIBID. Os espaços para discussão dos textos estudados, o planejamento das aulas com os bolsistas, a socialização de experiências, 


\section{autêntica}

o retorno à universidade, entre outras oportunidades de estudo, foram aspectos muito positivos e que influenciaram a carreira profissional desses professores, conforme relato desses docentes:

(...) foi uma troca, aprendi demais, pelos textos, pelas reuniões, pela convivência (P37EFE).

(...) eu ganhei um novo de gás depois que comecei a trabalhar com esses meninos do PIBID (...)

Eu estava meio desanimado e aí eu ganhei um novo gás (P43GA).

Eu acho que o PIBID veio somar muito, não só com os bolsistas, os estudantes do curso. Para a escola é com material que vem, as experiências novas (P38EFE).

Sobre isso, Tardif e Lessard (2012) corroboram afirmando que os profissionais constroem um conhecimento próprio, composto de saberes diversos advindos de diferentes fontes, tais como as experiências e vivências pessoais e sociais e também o trabalho, os quais irão constituir seu habitus.

É importante ressaltar ainda outro fato bastante significativo no que se refere às expectativas, revelado nas entrevistas: as falas dos docentes concentram-se nas oportunidades de estudo, trocas de experiências, melhorias na escola e nas práticas pedagógicas e, sobretudo, no desenvolvimento profissional docente. A questão financeira não foi citada como prioridade, como se nota na fala deste docente:

Gente, é muito mais que uma bolsa. Vou ter a chance de trabalhar com estagiários, os meninos cabecinha fresca começaram agora, estão aí aprendendo coisas novas e tal, isso vai me ajudar bastante. Então deixou de ser só a bolsa pra ser, pra ver, pra participar de uma proposta, segundo na época bem de vanguardista, bem diferente (P36IAHE).

É notável que a intervenção da universidade na escola básica, sobretudo para o professor supervisor, tornou-se um elemento motivador de reflexão, estudo e mudança de atitude no exercício da docência, ainda que a proposta do PIBID não esteja ao alcance de toda e equipe pedagógica.

Ainda assim, ao voltar o olhar para a sua prática, o professor passa por um processo crítico e reflexões muito relevantes emergem. Se por um lado ele se vê diante de desafios, por outro percebe seu amadurecimento, ao ser capaz de avaliar a sua prática, aceitar o novo e adaptar-se às mudanças. O PIBID é citado pelos professores supervisores como algo muito positivo, uma vez que Ihes dá motivação para os estudos, para a partilha de experiências, além de rica oportunidade de formação continuada.

Sobre isso, Nóvoa (2000, p. 38) afirma que "a formação contínua deve estimular uma perspectiva crítico-reflexiva, que forneça aos professores os meios de um pensamento autónomo e que facilite as dinâmicas de autoformação participada." A experiência de ser professor no PIBID ainda é citada pelos professores como algo desafiador, uma vez que ele tem que sair de sua zona de conforto, ao ver-se diante da necessidade de utilizar novas metodologias e novos recursos didáticos em suas aulas.

De acordo com o relato de um dos professores,

o PIBID funciona como uma formação continuada, porque trabalhamos as questões teóricas nas reuniões com os coordenadores e alunos na universidade, e isso tem [me] estimulado a realizar outras práticas em sala de aula (P46LLIE). 
Alguns professores relatam também que tinham dificuldade de mudar a prática pedagógica, sobretudo aqueles mais experientes, e que o programa lhes deu todo o suporte de que precisavam, pois representou um significativo apoio na sala de aula e nas discussões e debates sobre os processos de ensino e aprendizagem e no planejamento das aulas. Isso se evidencia na fala deste sujeito:

Eu não sou mais aquele professor que só eu que sei. A questão de dar voz aos alunos está a cada ano maior (P44HA).

A escola precisa criar meios para que a compreensão de que é extremamente importante dar voz aos alunos atinja toda a equipe pedagógica e não dependa de ações externas como o PIBID ou mesmo outras experiências formativas, que infelizmente, por questões já citadas, não se pode garantir que atingirão todos os professores da escola. Afinal, seja em qual série estiver matriculado, nenhum aluno ou aluna pode ser considerado um livro em branco, em cujas páginas o professor escreverá. E aqui estamos considerando como força transformadora não só a própria ação dos alunos, com suas bagagens, experiências, expectativas e frustrações, mas também aquela gerada pelo PIBID num campo de convergência que resulta do perceber o aluno como protagonista, deixando distante o papel que Ihe foi delegado como coadjuvante.

Outro aspecto relevante com relação à experiência do professor supervisor no PIBID diz respeito à conscientização de seu papel na formação dos futuros professores. Ser professor no PIBID vai além de ser apoio para os bolsistas, ou um mediador entre a universidade e a escola básica, a responsabilidade que assume ao tornar-se co-formador dos graduandos é evidente para a maioria dos professores ouvidos, como nos apontam estes professores:

A formação de professores é uma responsabilidade e tanta, e o professor supervisor tem que ser exemplo [...] tem que incentivar aqueles que estão graduando na área [...]. E vejo que a responsabilidade é muito grande mesmo (P46LLIE).

[...] E vejo que a responsabilidade é muito grande mesmo (P46LLIE).

Essa conscientização do professor supervisor vai ao encontro do que está definido no Edital da CAPESI2009, e que se refere aos objetivos do Programa, a saber:

a) incentivar a formação de professores para a educação básica, contribuindo para a elevação da qualidade da escola pública;

b) valorizar o magistério, incentivando os estudantes que optam pela carreira docente;

c) elevar a qualidade das ações acadêmicas voltadas à formação inicial de professores nos cursos de licenciatura das instituições públicas de educação superior;

d) inserir os licenciandos no cotidiano de escolas da rede pública de educação, promovendo a integração entre educação superior e educação básica;

e)proporcionar aos futuros professores participação em experiências metodológicas, tecnológicas e práticas docentes de caráter inovador e interdisciplinar e que busquem a superação de problemas identificados no processo de ensino-aprendizagem, levando em consideração o IDEB e o desempenho da escola em avaliações nacionais, como Provinha Brasil, Prova Brasil, SAEB, ENEM, entre outras;

f) incentivar escolas públicas de educação básica, tornando-as protagonistas nos processos formativos dos estudantes das licenciaturas, mobilizando seus professores como co-formadores dos futuros professores. (BRASIL, 2009, p.3). 


\section{autêntica}

A chegada do PIBID na escola representou um ânimo novo para o professor supervisor e para os alunos, mas não se pode dizer o mesmo em relação a todos os docentes da instituição. Vários entrevistados disseram, durante a conversa, que no início seus colegas viam com certa desconfiança as ações do PIBID na escola, porque não haviam sido selecionados para atuarem como supervisores ou simplesmente por medo do novo, da mudança. Embora cientes da necessidade de posturas colaborativas na escola, por razões diversas, alguns professores ainda se isolam e seguem com ações individualizadas, como já foi dito anteriormente. Os entrevistados relataram que o Programa gerou entre os pares um clima de insegurança, ciúmes e até inveja, como se os demais docentes tivessem sido preteridos ou se o processo de seleção do professor supervisor não tivesse sido democrático, como podemos verificar pelos seguintes depoimentos:

(...) alguns não aceitaram bem, porque o professor às vezes é meio vaidoso, meio medroso, esquece de olhar o conjunto, o todo (P57PAE).

(...) com eles a gente sabe que tem essas diferenças mesmo e a gente respeita essas diferenças, não é? (P47LLPE)

Felizmente, não foi em todas as escolas que isso ocorreu e muito menos com todos os professores. Na maioria das escolas onde o PIBID foi implantado, ele foi bem aceito, pois havia uma predisposição dos docentes para ações colaborativas. Farias (2006) nos lembra que um dos fatores que interferem diretamente no processo de ensino e aprendizagem é a cultura docente expressa também na forma como os professores e demais membros da escola se relacionam. Isso dito no contexto do PIBID significa que para que o Programa tenha êxito é necessário que o coletivo dos professores compreenda seus objetivos e colabore com sua dinâmica. Nas ocasiões em que faltava clareza quanto ao Programa, os professores viam o bolsista como um estagiário ou como um professor eventual. Os supervisores dizem que esse estranhamento inicial foi cedendo lugar à aceitação do PIBID à medida que sua proposta foi sendo conhecida e as atividades sendo executadas, como conta este professor: "Na primeira [oficina ministrada pelos bolsistas], a gente teve essa resistência inicial dos professores; na segunda, eles já queriam participar das oficinas e as últimas fluíram com naturalidade, pois eles já estavam entendendo" (P31LPE).

Um dado interessante diz respeito à boa colaboração dos professores no "Tempo Integral", sobretudo dos anos iniciais do Ensino Fundamental, onde as atividades são interdisciplinares e os docentes estão envolvidos em todas as áreas e atividades. O mesmo ocorre com professores de áreas afins aos projetos do PIBID. Esses tendem a colaborar mais, segundo os entrevistados, porque se identificam com as propostas e com o conteúdo que serve de referencial para as atividades, como se exemplifica pela fala do docente P41FE:

Na questão escolar não existe esse envolvimento total. Eles [os docentes de Física] ajudam (...). Os outros não, cada um na sua área.

A escola deve ser um lócus de planejamento, reflexão, ação coletiva, estudo e solidariedade, de acordo com Ferreira (2009). A autora diz ainda que a escola é um ambiente social que não só abriga grupos, mas que se configura num espaço de interlocuções que fortalecem a ação docente. Isso se comprova nessas falas:

Então, o corpo docente aqui apoia muito o trabalho que as meninas [licenciandas bolsistas do PIBID] vêm propondo aqui para a escola (P56PA).

(...) eu tenho que pedir a autorização do outro professor, da direção, então isso é sempre um pouquinho complicado, mas com planejamento é algo que é possível de ser superado (P42FLA). 
A partir das entrevistas com os professores supervisores, podemos inferir que a relação desses com seus pares no contexto do PIBID nem sempre é tranquila e sem tensões. Como discutimos anteriormente, várias são as razões que desfavorecem práticas cooperativas nas escolas, tais como a estrutura curricular, a falta de tempo, a rotatividade da equipe, a falta de diálogo, etc. No entanto, pode-se considerar que, aos poucos, a cultura docente vai caminhando no sentido da interação entre os pares, como pressupõe o processo educativo, e é nesse contexto de mudanças sutis que o PIBID vai se instalando e encontrando o seu espaço.

Temos insistido, seguindo o que dizem diversos autores, que as ações colaborativas são essenciais ao processo educativo, apesar de sabermos que muitos professores ainda mantêm práticas pedagógicas individuais ou em pequenos grupos. Foi dito também que alguns docentes reagem mal a situações novas no ambiente escolar e que veem com certa desconfiança as inovações, sobretudo se são introduzidas unilateralmente, sem a anuência dos professores e de demais atores da escola. Também já se falou que, em muitas escolas onde o PIBID foi desenvolvido, o Programa não teve aceitação imediata e que, somente aos poucos, seus objetivos tornaram-se conhecidos e sua proposta aceita. Ora, o PIBID introduziu na escola não apenas materiais pedagógicos e metodologias, mas estudantes de licenciaturas em preparação para o exercício futuro da profissão docente. Imagine a novidade que representa um grupo desses licenciandos de repente assumindo atividades didático-pedagógicas na sala de aula do professor supervisor, justamente sua zona de conforto. Há pouco chamamos a atenção para as falas em primeira pessoa, do tipo "minha sala", "minha turma", "meu conteúdo." Por isso, se os entrevistados dissessem que entre eles e os licenciandos havia uma relação impessoal ou com muitas tensões, não seria algo inesperado. No entanto, não foi o que ocorreu. Poucos entrevistados relataram que vez ou outra houve algum problema entre licenciando e professor supervisor, superado com muito diálogo, como se lê nas declarações abaixo:

Isso a gente precisou conversar sério com ele [licenciando] porque ele chegou a ofender um professor dentro da escola com essa atitude. O professor achou que ele estava sendo muito rude com ele e a gente teve esse entrave maior. Nesse momento, eu pensei em largar, pois eu não estava dando conta da minha função (P31LPE).

Pelos relatos, ficou claro também que os licenciandos que apresentaram problemas eram justamente aqueles que não estavam convictos da opção pela licenciatura, como nos conta este professor entrevistado:

(...) tem um ou outro [licenciando] que não está tão interessado, e são justamente esses que, passa um tempo, eles estão saindo. Fora isso, eu não tenho grandes problemas para estar desenvolvendo o projeto [PIBID] (P50MA).

Fora esses casos isolados, pode-se dizer que a relação entre professor supervisor e licenciandos era baseada no respeito mútuo, na cooperação e no profissionalismo. Os docentes falam dos bolsistas com amizade, orgulho e respeito, como se fala de um aluno muito querido. E se esse licenciando não é um "aluno" do professor supervisor, no sentido estrito do termo, o é pelo menos afetivamente, afinal o supervisor é um coformador desse futuro professor. Outro ponto interessante extraído da fala dos professores é que essa relação interpessoal desenvolvida no contexto do Programa se estende para além do PIBID. Muitos disseram que continuam em contato com os bolsistas, compartilhando informações e materiais, como afirma este entrevistado:

Então foi assim [a relação interpessoal com os licenciandos] muito produtiva e continua sendo, a gente continua trocando muita coisa, muito material, muita informação (P31LPE). 


\section{autêntica}

Esse recorte da entrevista que diz respeito à relação com os licenciandos nos permite inferir que os futuros professores, bolsistas do PIBID, iniciam a carreira docente de forma muito positiva, e que sua profissionalidade está definitivamente marcada pela experiência pedagógica do PIBID e pelas relações interpessoais estabelecidas com professores experientes no contexto escolar. É justamente isso que nos leva a refletir o pensamento de André e Hobold (2009 p.86):

Muitos fatores concorrem para a constituição da profissionalidade docente, tais como os pessoais e os profissionais, os cognitivos e afetivos, os individuais e coletivos. Esses múltiplos aspectos afetam e constituem as experiências escolares, familiares e profissionais, que compõem o repertório do 'saber fazer' de um professor, no qual estão incluídos conhecimentos, valores, habilidades, modos de percepção e de compreensão da realidade que o cerca.

A partir do que foi dito até aqui, pode-se concluir que a relação do professor supervisor com os licenciandos concorre para o êxito do PIBID, pois como tem sido pontuado, somente em contextos profissionais onde há parcerias é possível vislumbrar processos de ensino e a aprendizagem com maior qualidade.

Nessa dinâmica, com o desenvolvimento do projeto, os impactos do PIBID podem ser percebidos na rotina da escola. De acordo com avaliação dos professores, o Programa é muito bom para a universidade, que passa a ter um retrato da escola básica atual, e também é muito bom para a escola, em termos de recursos pedagógicos e metodologias. Através do relato destes docentes, constata-se que o PIBID se configurou como um importante suporte para auxiliar os alunos com dificuldades de aprendizagem e para aquisição de novas práticas:

(...) eu falei, gente, a gente tem que melhorar e nós vamos contar com esse apoio. A gente precisa disso [o PIBID]. E o negócio foi muito benéfico para a escola(P580E).

(...) a escola precisava de um apoio pedagógico e eu vi junto com os coordenadores do PIBID e tudo, que era uma boa coisa para a escola (P58QE).

(...) Motivação, foi esse problema de dificuldade mesmo que eu falo, então assim você ter o projeto vinculado à universidade com pessoas mais capacitadas, porque eu acredito que os professores, assim, eles têm mestrado, eles têm doutorado, então eles têm uma condição maior de(...) eles estão mais ligados a novidades, então isso foi uma motivação que pudesse trazer para gente um diferencial. Outra coisa, foi o fato de você ter pessoas para ajudar também nesse trabalho de recuperação desses meninos é uma perspectiva de você fazer alguma coisa diferente, de ver como que é na realidade... (P57PAE).

Segundo Luckesi (1996), adquirir conhecimentos não é compreender a realidade retendo informação, mas utilizar-se das informações para conhecer o novo e avançar, pois, quanto maior for o entendimento do mundo, mais satisfatória será a ação do sujeito sobre este.

Embora os aspectos positivos sejam citados pela maioria dos professores, foi mencionado também um mal-estar entre universidade e escola. Na visão de alguns docentes, a universidade tem uma aparente dificuldade para dialogar com a realidade da escola básica. Sobre essa questão, diz este professor:

Sempre nós [da escola básica] que procuramos a universidade, só que hoje é o contrário, a universidade que procura a escola, então se ela não se adequar às diretrizes da escola vai ser muito difícil a gente ter um movimento em paz, ainda mais para evitar um atrito (P59QE). 
Talvez, essa insegurança de alguns docentes da escola básica tenha sido gerada por outras experiências com a universidade, ou mesmo pela cultura escolar, que apesar de ter apresentado significativos avanços nos últimos anos, ainda demonstra dificuldades para abrir as portas das instituições. Mas por outro lado, quando essa parceria ocorre com êxito, como é o caso do PIBID, os benefícios são divulgados pela escola e pela universidade, o que contribui também para valorizar os docentes e as instituições. Na escola básica, os licenciandos apreendem não só a dinâmica da sala de aula, mas todo o aparato administrativo inerente à docência. Outro aspecto considerado positivo pelos entrevistados é o fato do Programa propiciar um planejamento conjunto da equipe pedagógica. Esses professores afirmam também que um dos maiores ganhos será percebido um pouco mais adiante, quando os futuros docentes estiverem ingressando profissionalmente na carreira, recém-formados, porém, com boa experiência na docência em escola pública: “a experiência do PIBID vai valorizar alguns anos de experiência para quem quer ser professor" (P42FLA).

De acordo com Nóvoa (2000), uma das medidas que podem contribuir para melhoria da qualidade da educação é a aproximação dos formadores de professores, ou seja, os professores universitários que lecionam nos cursos de licenciatura, com os professores que lecionam na Educação Básica, unindo forças, de modo que promovam um estudo e análise coletiva das práticas pedagógicas, o que é necessário para que haja de fato mudanças significativas na educação.

Para os graduandos, bolsistas do PIBID, o programa é reconhecido como significativo para os bolsistas porque permite seu protagonismo nas atividades que desenvolvem, apoiados pelo professor-supervisor, antes mesmo da experiência com o estágio obrigatório exigido pela instituição de ensino formadora. O que fica evidente é que assim como ocorre em toda relação, a fase de adaptação é complexa, permeada de incertezas, mas o planejamento responsável, as parcerias e a convivência respeitosa podem ser relevante para todos os envolvidos, assim como foi para a escola básica e a universidade, proporcionada pelo Programa Institucional de Bolsas de Incentivo à Docência (PIBID).

A partir da análise dos relatos dos docentes, ficou clara a importância do PIBID para a escola, sobretudo para a carreira desses professores, que declararam que depois de ingressarem no Programa sentiram-se motivados para seguir seus estudos autônomos ou acadêmicos. Muitos desejam ingressar no mestrado, inclusive alguns já ingressaram, porque tiveram a oportunidade de ter outra visão, talvez mais esperançosa, da educação pública. Tudo isso modificou as perspectivas dos professores, conforme pode-se comprovar nas falas destes professores:

(...) eu já não tinha vontade nenhuma de estudar mais, por essas coisas que vão te desanimando. E agora eu já penso em fazer mestrado, então assim alterou, impactou nesse sentido, de eu querer ir além, e aí o PIBID deu essa nova vida (P57PAE).

Hoje eu penso em continuar na licenciatura e quero fazer um mestrado para me aprimorar em alguma coisa, e porque eu quero melhorar na minha profissão (P32BA).

As entrevistas revelam também que, por meio do PIBID, a relação com os pares melhorou no espaço da escola, pois a motivação para desenvolver as propostas do Programa de forma interdisciplinar fez com que se estabelecessem parcerias entre os colegas. Toda essa mobilização na escola, na sala de aula e na carreira profissional do professor supervisor do PIBID é um rico objeto de análise pelas novas possibilidades e perspectivas que emergem, a partir da reflexão e mudança de atitude em relação à prática educativa.

De acordo com Imbernón (2011, p.75) “o contato da formação com a prática educativa faz com que o conhecimento profissional se enriqueça com outros âmbitos: moral, ético (por todas as características políticas da educação), tomada de decisões, discernimento sobre o que deve ser feito em determinadas situações". 


\section{autêntica}

É pertinente afirmar ainda que o PIBID melhora as perspectivas da carreira também para o bolsista. No contato real com os professores da escola básica, com os alunos, com o contexto escolar, a formação e prática educativa tornam-se muito significativas por acontecer em lócus. Toda essa dinâmica formativa proporcionou aos bolsistas e aos professores supervisores do PIBID oportunidades de reflexão, mudança de postura, adoção de novas práticas, processos de formação inicial e continuada, e desenvolvimento profissional. Sobre essa questão, Abdalla (2006, p.12) afirma que "se a escola é um lugar de aprendizagem e de ensino, professores aprendem, também, no contexto das práticas de gestão e das relações sociais que a estrutura e a dinâmica organizacional da escola implementam e mantêm".

Alguns relatos apontam a boa receptividade das escolas com a proposta do PIBID, o que de certa forma, contribui para que haja mais envolvimento:

A minha escola é muito receptiva, desde a administração até os próprios colegas professores, como eu já considerei, eles são receptivos e solícitos ao trabalho do PIBID ( P46LLIE).

(...) veio a ideia de trabalhar com outras disciplinas, então a gente comprovou que era possível dentro do planejamento do ano. Sem alterar a rotina, isso me motivou a correr atrás dos parceiros dentro da escola. E tem funcionado (P31LPE).

No entanto, as entrevistas revelaram também que em algumas realidades não aconteceu o envolvimento de toda a equipe do PIBID, ainda assim os docentes avaliam como positivo o apoio que receberam de seus pares e da direção da escola, além do contato com a universidade. De qualquer forma, a inserção do PIBID na escola básica é algo novo que rompe com alguns paradigmas. A cultura escolar estava acostumada a acatar as decisões de que os professores fossem retirados da escola para participarem de cursos de capacitações, palestras, seminários e outros eventos que muitas vezes não correspondiam às expectativas dos participantes e da realidade da escola, parecia impossível que a escola desse conta desse papel.

Sob esse ponto de vista, há de se considerar inovadora a proposta do PIBID, visto que é uma prática que permite ao professor da educação básica estar em constante formação e em diálogo permanente com instituições formadoras de docentes, ao mesmo tempo em que lhe permite contribuir de forma indelével na formação inicial dos licenciandos. A inovação traz, não a ideia de "simplesmente agregar novos elementos, mas romper com o paradigma dominante, introduzindo novas alternativas que quebrem com a estrutura tradicional do trabalho e interfiram nos resultados de aprender e ensinar numa perspectiva emancipatória", de acordo com Cunha (2002, p. 90-91).

Certamente, de todos os elementos de análise e reflexão sobre a pesquisa, o de maior relevância talvez seja o fato da formação continuada do professor supervisor acontecer no contexto escolar com todos os desafios do dia a dia, junto aos alunos, através das metodologias adotadas, do planejamento, da busca de parcerias, da reflexão crítica e da mudança de pensamento e de atitude. 


\section{CONSIDERAÇÕES FINAIS}

A texto aqui apresentado, apenas um recorte da pesquisa Desenvolvimento Profissional Docente e Inovação Pedagógica: Estudo Exploratório sobre Contribuições do PIBID, trouxe à tona muito mais que o impacto do PIBID na carreira profissional dos professores supervisores. Os dados coletados e as análises criteriosas dessas informações revelaram que os docentes, em sua grande maioria, identificam-se totalmente com a profissão escolhida e que, apesar de cientes dos inúmeros desafios que encontram no dia a dia da carreira, sobretudo na escola pública, continuam acreditando no potencial transformador da educação.

Retomando alguns pontos recorrentes na fala dos sujeitos, podemos destacar pelo menos três principais aspectos positivos em relação à implantação do PIBID nas escolas onde atuam os entrevistados. Primeiramente, há que se falar da formação continuada. Através das discussões promovidas pelo Programa, os docentes tomaram consciência do desenvolvimento de sua profissão e de como eles mesmos são corresponsáveis pela trajetória de sua carreira. Consequentemente, após se (re)aproximarem da universidade, muitos entrevistados tencionam agora continuar seus estudos por sentirem que vale a pena investir na autoformação. Por fim, esses docentes supervisores do PIBID compreenderam a importância de sua participação e atuação nos projetos, pois o Programa proporciona ganhos para a comunidade escolar, para si mesmos e, principalmente, para os licenciandos, futuros professores, cuja formação prática se deve, em parte, ao papel que desempenham junto ao PIBID.

Os desafios que se apresentam cotidianamente na escola pública requerem a atuação de equipes pedagógicas focadas em práticas colaborativas e interdisciplinares. Também nesse ponto os docentes disseram que o PIBID vem auxiliando a escola a superar práticas isoladas rumo a uma práxis cooperativa. Reconhecem que o PIBID apresenta-se como uma boa contribuição para a escola básica, visto que agrega valores e experiências para todos os envolvidos, além de levar melhorias para a instituição, na forma de recursos materiais e novas metodologias.

Neste texto, discutiram-se aspectos inerentes aos "Sujeitos da Profissão", descritor que se refere diretamente ao professor da escola básica, responsável pelo projeto do PIBID em sua instituição e nomeado no âmbito do Programa como "Professor Supervisor". Contudo, é imperativo que relacionemos esse subsubnó ao segundo descritor-título da pesquisa "Inovação Pedagógica", constatada na medida em que o PIBID proporciona ao licenciando vivenciar a experiência da escola básica em seu contexto real, sob a tutela de um professor experiente que lhe serve de referencial e que abre as portas da sala de aula para dialogar com a universidade. Dessa forma, exercitando a tão apregoada e necessária parceria pedagógica, a escola básica, através do PIBID, ajuda as instituições superiores a formar novos professores para a educação pública brasileira, ao mesmo tempo em que o Programa dá novo alento o professor experiente da educação básica. Pelo que se constatou até aqui, o PIBID é uma experiência institucional inovadora e positiva para todos os envolvidos. 


\section{DOCENTE}

\section{autêntica}

\section{REFERENCIAL TEÓRICO}

ABDALLA, Maria de Fátima Barbosa. O senso prático de ser e estar na profissão. São Paulo: Cortez, 2006.

ANDRÉ, Marli e HOBOLD, Márcia. Representações Sociais de estudantes de licenciatura sobre a profissão e a profissionalidade docente. Revista da FAEEBA- Educação e Contemporaneidade, Salvador, v.18,.n 32, p.63-93. Jul/dez, 2009.

BRASIL. Edital PIBID 2009 - Fundação CAPES. Disponível em: <https://www.capes.gov.br/images/stories/ download/bolsas/Edital02 PIBID2009.pdf>. Acesso em: 19/10/2016.

BRASIL. Decreto $n^{\circ} 7.219$ de 24 de junho de 2010. Dispõe sobre o Programa Institucional de Bolsas de Iniciação à Docência - PIBID e dá outras providências. Diário Oficial da União. Brasília: Casa Civil da Presidência da República, 2010. Disponível em http:/www.planalto.gov.br/ccivil_03/_Ato2007 2010/2010/Decreto/D7219.htm>

BRASIL. Lei de Diretrizes e Bases da Educação Nacional - LDBN Lei n 9.394 de 20 de dezembro de 1996.

CUNHA, Maria Isabel. I. In: LEITE, Denise B.C; MOROSINI, Marília.(orgs) Universidade futurante: produção do ensino e inovação. 2. ed. Campinas, SP: Papirus, 2002.

DAY, C. Desenvolvimento profissional de professores: os desafios da aprendizagem permanente. Porto: Porto Editora, 2001. 351p.

FARIAS, Isabel Maria Sabino de. Inovação, mudança e cultura docente. Brasília: Liber Livro, 2006.

FERREIRA, Liliana Soares. Professoras e professores como autores de sua professoralidade: a gestão do pedagógico na sala de aula. Revista Brasileira de Política e Administração da Educação, v.25, n³, p.425-438, Porto Alegre, RS, set/dez.2009.

FINO, C. N. Inovação pedagógica: significado e campo (de investigação). In: MENDONÇA, Alice e BENTO, António V. (org.) Educação em tempo de mudança. Funchal, Portugal: Grafimadeira, p. 277-287. 2008

IMBERNÓN, Francisco. Formação docente e profissional: formar-se para a mudança e a incerteza. 9a ed. São Paulo: Cortez, 2011. 127p. (Coleção questões da nossa época; v. 14).

LUCKESI, Cipriano Carlos; PASSOS, Elizete Silva. Introdução à filosofia: aprendendo a pensar. São Paulo: Cortez, 1996.

NÓVOA, A. A formação de professores e a profissão docente. In: Os professores e a sua formação. 2 ed. Lisboa: Dom Quixote, 1995. p. 16-33

NÓVOA, António (Org.). Concepções e práticas de formação contínua de professores. In. A. Nóvoa, (ED). Formação de professores e trabalho pedagógico. Lisboa: Universidade de Lisboa; Pacheco, J. A. \& Flores, M. A., 2000 .

OLIVERI, Andrezza M., JARDILINO, José R.L., DINIZ, Margareth. Seduzido fui, seduzido fiquei: o PIBID sob a perspectiva do professor iniciante - a experiência na Região dos Inconfidentes. In: FARIAS, Isabel M. S., JARDILINO, José R.L., SILVESTRE, Magali A.(Orgs.) Aprender a ser professor: aportes de pesquisa sobre o PIBID. Jundiaí, Paco Editorial, 2015. 
